I commenced this Address by asking you to follow me in an attempt to trace the path which has been followed by a scientific idea, in its long and slow progress from the position of a probable hypothesis to that of at established law of nature. Our survey has not taken us into very attractive regions; it has lain, chiefly, in a land flowing with the abominable, and peopled with mere grubs and mouldiness. And it may be imagined with what smiles and shrugs, practical and serious contemporaries of Redi and of Spallanzani may have commented on the waste of their high abilities in toiling at the solution of problems which, though curious enough in themselves, could be of no conceivable utility to mankind.

Nevertheless you will have observed that before we had travelled very far upon our road there appeared, on the right hand and on the left, fields laden with a harvest of golden grain, immediately convertible into those things which the most sordidly practical of men will admit to have value-viz., money and life.

The direct loss to France caused by the Pébrine in seventeen years cannot be estimated at less than fifty millions sterling; and if we add to this what Redi's idea, in Pasteur's hands, has done for the wine-grower and for the vinegar-maker, and try to capitalise its value, we shall find that it will go a long way towards repairing the money losses caused by the frightful and calamitous war of this autumn. And as to the equivalent of Redi's thought in life, how can we over-estimate the value of that knowledge of the nature of epidemic and epizöotic diseases, and consequently of the means of checking, or eradicating, them, the dawn of which has assuredly commenced?

Looking back no further than ten years, it is possible to select three (1863, 1864, and 1869) in which the total number of deaths from scarlet-fever alone amounted to ninety thousand. That is the return of killed, the maimed and disabled being left out of sight. Why, it is to be hoped that the list of killed in the present bloodiest of all wars will not amount to more than this! But the facts which I have placed before you must leave the least sanguine without a cloubt that the nature and the causes of this scourge will, one day, be as well understood as those of the Pébrine are now ; and that the long-suffered massacre of our innocents will come to an end.

And thus mankind will have one more admonition that "the people perish for lack of knowledge;" and that the alleviation of the miseries, and the promotion of the velfare, of men must be sought, by those who will not lose their pains, in that diligent, patient, loving study of all the multitudinous aspects of Nature, the results of which constitute exact knowledge, or Science. It is the justification and the glory of this great meeting that it is gathered together for no other object than the advancement of the moiety of science which deals with those phenomena of nature which we call physical. May its endeavours be crowned with a full measure of success!

\section{PROFESSOR H. E. ROSCOE'S OPENING ADDRESS TO} SECTION $\mathrm{B}$

GENTLEMEN,--In the midst of the excitement of the horrible war in which the two most scientific nations of the continent are now plunged, and in which even the Professors of Chemistry and their students take a humane part, let us endeavour to turn our thoughts into channels more congenial to the scientific inquirer, and allow me to recount to you, as far as I am able, the peaceful victories which, since oul last meeting in Exeter, have been achieved in our special department of chemistry. And here may I remind you of the cosmopolitan character of science, of the fact that it is mainly to the brotherly intercourse of those interested in science, and in its applications to the arts and manufactures in different countries, that we must look as the small but living fire which in the end will surely serve to melt down national animosities, and to render impossible the breaking out of disasters so fatal to the welfare of humanity as that of which we are now unfortunately the spectators.

With regard to the position of chemical science at the present moment, it will not take a careful observer long to see, that in spite of the numerous important and brilliant discoveries of which every year has to boast, we are really but very imperfectly acquainted with the fundamental laws which regulate chemical actions, and that our knowledge of the ultimate constitution of matter upon which those laws are based is but of the most elementary nature. In proof of this, I need only refer to the differcnt opinions expressed by onr leading chemists in a discussion which lately took place at the Chemical Society on the subject of the Atomic Theory. The President (Dr. Williamson) delivered a. very interesting lecture in which the existence of atoms was treated as "the very life of chemistry." Dr. Frankland, on the other hand, states, that he cannot understand action at a distance between matter separated by a vacuous space, and, althongl generally granting that the atomic theory explains chemical facts, yet he is not to be considered as a blind believer in the theory, or as unwilling to renounce it if anything better presented itself. Sir B. C. Brodie and Dr. Odling both agree, that the science of chemistry neither requires nor proves the atomic theory; whilst the former points out that the true basis of this science is to be sought in the investigation of the laws of gaseous combination, or the study of the capacity of bodies for heat rather than in committing ourselves to assertions incapable of proof by chemical means.

Agreeing in the main myself with the opinions of the last chemists, and believing that we must well distinguish between fact and theory, I would remind you that Dalton's discovery of the laws of multiple and reciprocal proportions (I use Dr. Odling's phraseology), as well as the differences in the power of hydro. gen replacement in hydrochloric acid water, ammonia, and marsh gas, are facts, whilst the explanation upon the assumption of atoms is, as far as chemistry is as yet advanced, a theory.

If, however, the existence of atoms cannot be proved by chemical phenomena, we must remember that the assumption of the atomic theory explains chemical facts, as the undulatory theory gives a clear view of the phenomena of light; thus, for instance, one of the most important facts and relations of modern chemistry, which it appears difficult if not impossible to explain without the assumption of atoms, is that of Isomerism. How otherwise than by a different arrangement of the single constituent particles are we to account for several distinct substances in which the proportions of carbon, hydrogen, and oxygen are the same? Why, for instance, should 48 parts, by weight, of carbon, 10 of hydrogen, and 16 of oxygen, united together, be capable of existing as three different chemical substances, unless we presuppose a different statical arrangement of the parts by whicli these differences in the deportment of the whole are rendered possible. If, then, it be true that chemistry cannot give us positive information as to whether matter is infinitely divisible and therefore continuous, or consists of atoms and is discontinuous, we are in some degree assisted in this inquiry by deductions from physical phenomena which have been recently pointed out by the genius of Sir William Thomson. Hc argues from four clifferent classes of physical phenomena, and comes to the conclusion not only that matter is discontinuous, and therefore that atoms and molecules do exist, but he even attempts to form an idea of the size of these molecules, and he states that in any ordinary liquid, transparent or seemingly opaque solid, the mean distance between the centres of contiguous molecules is less than the 100 millionth, and greater than the 2,000 millionth of a centimetre. Or, to form a conception of this coarse-grainedness, imagine a raindrop, or globe of giass as large as a pea, to be magnified up to the size of the earth, each constituent molecule being magnified in the same proportion, the magnified structure would be coarser grained than a heap of small shot, but probably less coarse grained than a heap of cricket balls. There is, however, another class of physical considera. tions which renders the existence of indivisible particles more than likely. I refer to the mechanical theory of gases, by means of which, thanks to the labours of eminent English and German philosophers, all the physical properties of gases-their equal expansion by heat, the laws of diffusion, the laws of alteration of volume under pressure--can be shown to follow from the simple laws of mechanical motion. This theory, however, presupposes the existence of molecules, and in this direction, again, we find confirmation of the real existence of Dalton's atoms. Indeed, it has been proved that the average velocity with which the particles of oxygen, nitrogen, or common air are continually projected forwards amounts, at the ordinary atmospheric pressure, to 50,000 centimetres per second, whilst the average number of impacts of each of these molecules is 5,000 million per second.

The mention of the molecular motions of gases will recall to the minds of all present the great loss which English science has this year sustained in the death of the discoverer of the laws of gaseous diffusion. Throughout his life Graham's aim was the advancement of our lnowledge in the special subject of the molecular properties of gases. With this intent he unceasingly lahoured up to the moment of his death, in spite of failing health and pressure of official business, unfolding for posterity some of the most difficult as well as the most interesting secrets of nature in this branch of our science. "What do you think," he writes 
to Hoffmann, "of metallic hydrogen, a white magnetic metal?" and yet now, through his labours, the fact of the condensation of hydrogen in the solid state. by metallic palladium, and to a less extent by other metals, has become familiar to all of us. Then, again, I would remind you of Graham's recent discovery of the occlusion of hydrogen gas in certain specimens of meteoric iron, whilst earth-manufactured iron contains, not hydrogen, but absorbed carbonic oxide gas, proving that the meteorite had probably been thrown out from an atmosphere of incandescent hydrogen, existing under very considerable pressure, and therefore confirming in a remarkable degree the conclusions to which spectrum analysis had previously led us. The position in the ranks of British science left by Graham's death will not be easily filled up. He accomplished to a certain extent for dynamical chemistry what Dalton did for statical chemistry; and it is upon his experimental researches in molecular chemistry that Graham's permanent fame as one of England's greatest chemists, will rest.

As closely connected with the above subjects I have next to mention a most important research by Dr. Andrews, of Belfast, which, marking an era in the history of gases, shows us how our oldest and most cherished notions must give way before the touchstone of experiment. No opinion would appear to have been more firmly established than that of the existence of three separate states or conditions of matter, viz. the solid, the liquid, and the gaseous. A body capable of existing in two or more of these states was thought to pass suddenly from one to the other by absorption or emission of heat, or by alterations of the superincumbent pressure. Dr. Andrews has shown us how false are our views on this fundamental property of matter, for he has proved that a large number of, and probably all, easily condensible gases or vapours possess a critical point of temperature at and above which no increase of pressure can be made to effect a change into what we call the liquid state, the body remaining as a homogeneous fluid. Whilst below this critical temperature certain increase of pressure always effects a separation into two layers of liquid and gaseous matter. Thus with carbonic acid the point of critical temperature is $30^{\circ} .92 \mathrm{C}$., and with each given substance this point is a specific one, each vaponr exhibiting rapid changes of volume and flickering movements when the temperature or pressure was changed, but showing no separation into two layers. Under these circum stances it is impossible to say that the body exists either in the state of a gas or of a liquid; it appears to be in a condition intermediate between the two. Thus carbonic acid under the pressure of 108 a tmospheres, and at $35^{\circ} 5^{\prime} \mathrm{C}$., is reduced to $\frac{1}{4}$ of the volume which it occupies at one atmosphere: it has undergone a regular and unbroken contraction, and it is a uniform fluid. If we now reduce the temperature below $31^{\circ} \mathrm{C}$., the liquid condition is assumed without any sudden change of volume or any abrupt evolution of heat. We can scarcely too highly estimate the value of the researches of Andrews.

As examples of the power which modern methods of research give of grappling with questions which only a few years ago were thought to be insoluble, I may quote the beautiful observations, now well known, by which Lockyer determined the rate of motion on the sun's surface, together with those of Frankland and Lockyer respecting the probable pressure acting in the different layers of the solar atmosphere; and, lastly, the results obtainer by Zöllner respecting solar physics, and especially the probable absolute temperature of the sun's atmosphere, as well as that of the internal molten mass. These last results are so interesting and remarkable, as being arrived at by the combination of recent spectroscopic observation with high mathematical analysis, that $I$ may perhaps be permitted shortly to state them. Starting from the fact of the eruptive nature of a certain class of solar protuberances, Zöllner thinks that the extraordinary rapidity with which these red flames shoot forth proves that the hydrogen of which they are mainly composed must have burst out from under great pressure; and, if so, the hydrogen must have been confined by a zone or layer of liquid from which it breaks loose. Assuming the existence of such a layer of incandescent liquid, then applying to the problem the principles and methods of the mechanical theory of gases, and placing in his formulæ the data of pressure and rate of motion as observed by Lockyer on the sun's surface, Zöllner arrives at the conclusion that the difference of pressure needed to produce an explosion capable of projecting a prominence to the height of $3^{\circ} \circ$ minutes above the sun's surface (a height not unfrequently. noticed) is 4,070,000 atmospheres. This enormous pressure is at tained at a depth of I 39 geographical miles under the sun's surface, or at that of the $\frac{1}{6.5}$ part of the sun's semi-diameter. In order to produce this gigantic pressure, the difference in temperature between the enclosed hydrogen and that existing in the solar atmosphere amounts to $74,710^{\circ} \mathrm{C}$.! In a similar way Zöllner calculates the approximative absolute temperature of the sun's atmosphere, which he finds to be $27,700^{\circ} \mathrm{C}$; ; a temperature about eight times as high as that given by Bunsen for the oxyhy. drogen flame, and one at which iron must exist in a permanently gaseous form.

Passing on to more purely chemical subjects, we find this year signalized by the redetermination of a most important series of chemical constants, viz. that of the heat of chemical combination by Julius Thomsen, of Copenhagen. This conscientious experimentalist asserts that the measurements of the heat evolved by neutralizing acids and bases hitherto considered most correct, viz. those made with a mercury calorimeter by Favre and Silbermann, differ from the truth by 12 per cent. ; whilst the determination by these experimenters of the heat of solution of salts is frequently 50 per cent. wrong. As the result of his numerous experiments, Thomsen concludes that when a molecule of acid is neutralized by caustic alkali the heat evolved increases nearly proportionally to the quantity of alkali added until this reaches $1, \frac{1}{2}, \frac{1}{3}, \frac{1}{4}$ of a molecule of alkali, according as the acid is mono-; di-, tri-, or tetra-basic. Exceptions to the law are exhibited by silicic, and also partly by bnracic, orthophos. phoric, and arsenic acids. In the two latter, the heat of combination is proportional for the two first atoms of replaceable hydrogen, but much less for the third atom. A second unexpected conclusion which Thomsen draws from his calorific determinations is, that sulphuretted hydrogen is a monobasic acid, and that its rational formula is therefore $\mathrm{HSH}$.

Another important addition made to chemistry since our last meeting is a new, very powerful, and very simple form of galvanic battery discovered, though not yet described, by Bunsen. In this second Bunsen's battery only one liquid, a mixture of sulphuric and chromic acids, and therefore no porous cells, are employed. The plates of zinc and carbon can all be lowered at once into the liquid and raised again at will. The electromotive force of this battery is to that of Grove (the most powerful of known forms) as 25 to 18 ; it evolves no fumes in working, and can be used for a very considerable length of time without serious diminution of the strength of the current, so that Bunsen writes me that no one who has once used the new battery will ever think of again employing the old forms. I had hoped to be able to exhibit to the Section this important improvement in our means of producing a strong current; but war has demanded the use of other batteries, and Bunsen has been unable to send me a set of his new cells.

Amongst the marked points of interest and progress in inorganic chemistry during the past year, we have to notice the preparation of a missing link amongst the oxy-sulphur acids by Schützenberger. It is the lowest known, and may be called Hydro-Sulphurous Acid, $\mathrm{H}_{2} \mathrm{SO}_{2}$. The sodium salt, $\mathrm{Na}$ H SO is obtained by the action of zinc on the bisulphite. As might be expected, it possesses very powerful reducing properties, anil bleaches indigo rapidly. The metallic vanadates have also been carefully examined, and the existence of three distinct series of salts proved, corresponding to the phosphates, viz. the ortho or tribasic vanadates, the pyro or tetra-basic vanadates, and the meta or monobasic yanadates. Of these, the ortho-salts are most stable at a high temperature, whilst at the ordinary atmospheric temperature the meta-salts are most stable. In the phosphorus series, as is well known, the order of stability is the reverse ; and thus the points of analogy and of difference between phosphorus and vanadium become gradually apparent.

As an illustration of the results of modern organic researchfor in viewing the year's progress in this ever-widening branch of chemistry it is impossible to do more than give a few illustrations-I may quote Baeyer's remarkable investigations on Mellitic Acid. Originally discovered by Klaproth in honeystone or mellite (a substance which yet remains the only source of the acid), mellitic was supposed to be a four-carbon acid. Baeyer has quite recently shown that the acid contains 12 atoms of carbon, or has a molecular weight three times as great as was originally supposed. He has shown that mellitic acid is benzolhexacarbonic acid, $\mathrm{C}_{12} \mathrm{H}_{6} \mathrm{O}_{12}$, or benzol in which the 6 atoms of hydrogen are replaced by the monad radical carboxl $(\mathrm{C} \mathrm{O}(1 \mathrm{H})$; as benzoic is Benzol Monocarbonic acid, or benzol in which one of hydrogen is replaced by carboxyl. The most interesting portion of Baeyer's research, however, lies in the intermediate acids, partly new and partly acids already prepared, which he has 
shown lie between mellitic and benzoic acisl, and in which from 1 to 6 atoms of hydrogen in benzol are respectively replaced by carbaxyl. Nor is this all, for he has proved that, with two exceptions, each of these six acids is capable of existing in three isomeric modifications, thus giving us an insight into the arrangement of the molecule of these aromatic compounds. For the simplest mode of explaining these numerous isomers is that given by Baeyer in the different order in which the several atoms of hydrogen in the benzol molecule are replaced. Thus in the first or ortho series, the hydrogen atcms in benzol being numbered in regular succession, they are replaced in the same regular succession. In the second or meta series, the order is $x, 2,3,5$, \&c., whilst the third or para series take open orler as $I, 2,4,5$. Thus we have :-

\begin{tabular}{|c|c|c|c|}
\hline $\mathrm{C}_{\mathrm{x} 2} \mathrm{H}_{3} \mathrm{O}_{\mathrm{x} 2}$ Hexeabasi & $\begin{array}{l}\text { Ortho Series. } \\
\text { io Melitic or } \\
\text { Genzolhexacarbonic. }\end{array}$ & Para Serís. & Heta Series. \\
\hline $\mathrm{C}_{\mathrm{r}} \mathrm{H}_{6} \mathrm{O}_{10}$ Penta & Unknown. & 一 & - \\
\hline $\mathrm{C}_{\mathrm{ro}} \mathrm{IH}_{6} \mathrm{O}_{8}$ Tetra. & $\begin{array}{l}\text { Pyromellitic or } \\
\text { íenzoltetracarbonic. }\end{array}$ & Isopyromellitic. & Unknown. \\
\hline $\mathrm{C}_{9} \mathrm{H}_{6} \mathrm{O}_{6}$ Tri & $\begin{array}{l}\text { Trimesinic, or } \\
\text { Benzoltricarbonic. }\end{array}$ & Hemimellitic. & Trimellitic. \\
\hline $\mathrm{C}_{8} \mathrm{H}_{6} \mathrm{O}_{4} \mathrm{Di}$ & Phtalic or & Isophtalic. & Tetraphtalic. \\
\hline $\mathrm{C}_{7} \mathrm{H}_{6} \mathrm{O}_{2}$ Mono & $\left\{\begin{array}{l}\text { Benzoic or } \\
\text { Benzol }\end{array}\right.$ & & \\
\hline
\end{tabular}

Amongst the most interesting series of new organic bodies are those in which tetrad silicon partly replaces carbon. Our knowledge of these substances is gradually becoming more comliete; the last new member prepared by Friedel and Larlenburg is silico-propionic acid $\mathrm{C}_{2} \mathrm{H}_{5} \mathrm{Si} \mathrm{O}_{2} \mathrm{IH}$, the first of a series of carbo-silicic acids containing the raclical $\mathrm{Si} \mathrm{O}_{2} \mathrm{H}$.

The interestiurs researches of Matthiessen and Wright on Morphine and Cudeine have thrown a new light on the constitution of these opium alkaloids. Treated with hydrochloric acid, murphine ln:es oise molecule of water, and gives rise to a new b. se, called ap r norphine. Thus:

$$
\mathrm{C}_{17} \mathrm{H}_{10} \mathrm{NO}_{3}=\mathrm{H}_{2} \mathrm{O}+\mathrm{C}_{17} \mathrm{II}_{17} \mathrm{NO}_{2}
$$

which differs in a remarkable manner from morphine, both in its chemical and physiological actions, being soluble in alcohol, ether, and chloroform, whereas morphine is nearly insolub?e, and acting as the most powerful emetic known, $\frac{1}{15}$ th of a grain producing vomiting in less than ten minutes. Codeine, which only differs from morphine by $\mathrm{CH}_{2}$, also yields apomorphine on treatment at a livin temperature with hydrochloric acid, methylchloride being at the same time eliminated.

An important application of the deliydrating and carbon condensing power of zinc chloride, long known in its action or alc.hol to produce etber, has been made by Kekulé in the reduplication of aldehydz to form croton-aldehyde with loss of water. $2\left(\mathrm{C}, \mathrm{H}_{6} \mathrm{O}\right)-\mathrm{H}_{\mathrm{n}} \mathrm{O} \mathrm{O}=\mathrm{C}_{4} \mathrm{H}_{6} \mathrm{O}$

This croton-aldehyde is also probably formed as an intermediate product in the mantancture of chloral from aldehyde, and gives rise to the formation of crotonchloral

$$
\mathrm{C}_{4} \mathrm{H}_{3} \mathrm{Cl}_{3} \mathrm{O} \text {. }
$$

The discovery of the sedative properties of chloral-hydrate by Lisbreich marks an era in medical chemistry second only to the cliscovery of the anzesthetic properties of chloroform. Chloral not only combines with water to form a solid hydrate, but also forms solid alcoholates; but the se bodies appear to possess quite different medicinal properties from the liydrate, and it is important that no alcoholate should be present in the officinal preparation. The chemistry of colouring matters has lately received an enormous impetus in the working of the brilliant discovery of the production of artificial alizarine, the rolouring matter of madder, by Messrs. Graebe and Liebermann. This discove:y, announcer at our last meeting, is of the highest importance, whether we regard its scientific interest or its practical and commercial value, and it differs from all the former results which have been brought about by the application of science to the production of colouring matters, inasmuch as this has reference to the artificial production of a natural vegetable culouring substance which has been used as a dye from time immemorial, and which is still employed in enormous quantities for the production of the pink, purple, and black colours which are seen everywhere on printed calicoes. During the past year much progress has been made in the practical working of the processes by which this colouring matter is obtained from the hydrocarbon anthracene contained in coal tar, and new and more economical plans for effecting the transformation have been independently proposed by Perkin and Caro, anl Schorlemmer and Dale. The theoretical investigation of the reaction, and especially of the nature of some other peculiar products formed in addition to alizarine, which render the artificial colouring matter different from natural alizarine, has been carried out by Mr. Perkin, and especially by Dr. Schunck. As we are promised papers on this subject from both these gentle. men, I need not now enter further into these interesting questions.

The surest proof of perfection in a manufacture is the degree in which the waste products are utilised, and in which the processes are made continuous. One by one the imperfections of the original discovery are made to disappear, and the products which were wasted become sources of profit, whilst in many cases their utilisation alone renders possible the continuance of the manufacture in the midst of a rapidly increasing district. 'The Section will have the opportunity of inspecting the practical working of at lcast two of the most valuable of these new processes which have lately been introduced into our nicst important chemical manufacture, that of alkali. The first of these has been at work for some time; it is that of the recovery of sulphur from the vat waste, that bete noire of the alkali makers and of their neighbours. Dr. Mond has now, I believe, satisfactorily solved the difficult problem of economically regaining the sulphur by oxidising the insolnble monosulphide of calcium in the lixiviating vat itself to the soluble hyposulphite, and decomposing this by hydrochloric acid, when all the sulphur is deposited as a white powder.

The second of these discoveries relates to the recovery or regeneration of the black oxidc of manganese, used for the evolution of chlorine in the manufacture of bleaching powder. This subject has long attracted the attention of chemists, and a feasible though somewat costly process, that of Dunlop, has been at work for some time at Messrs. Tennant's works at St. Rollox.

During the last year a very beautifully simple and economical process, proposed by Mr. Weldon, and first successfully carried out on a practical scale in M. essrs. Gamble's works at St. Helen's, has quickly obtained recognition, and is now worked by more than thirty-seven firms throughout the kingdom. The principle upon which this process depends was explained by $\mathrm{Mr}$. Weldon at the Exeter meeting. It depends on the fact that although when alone the lower oxides of manganese camnot be oxidised by air and steam under the ordinary pressure to the state of dioxide, yet that this is possible when one molecule of lime is present to each molecule of oxide of manganese. The manganous oxide is precipitated from the still liquors with the above excess of lime, and by the action of steam and air on this a black powder consisting of a compound of manganese, dioxide and lime, $\mathrm{MnO}_{2} \mathrm{C}_{\mathrm{a}} \mathrm{O}$, or calcium manganite, is formed. This, of course, is capable of again generating chlorine, on adrlition of hydrochloric acid, and thus the chlorine process is male continuous with a working loss of only $2 \frac{1}{4}$ per cent. of manranese. The Section will have the advantage of seeing Mond's prozess at work at Messrs. Hutchinson and Weldon's process, at Messrs. Gaskell, Deacon, and Cu.'s, at IVidnes.

A third process, which may possibly sti!l further revolutionise the manufacture of bleaching powder, is the direct production of chlorine from hydrochloric acid without the use of manganese at all. In presence of oxygen and of certain metallic oxides, such as oxide of copner, hydroc!nloric acid gas parts at a red heat with all its hydrogen, water and chlorine being formed. This interesting reaction is employed by Mr. Deacon, for the direct manufacture of bleaching powder from the gases issuing directly from the salt-cake furnace. Air is admitted together with hydrochloric acid gas, and the mixture is passed over red. hot bricks impregnated with copper salt. The oxide of copper acts as by contact and remains unaltered, whilst the chlorine, watery vapour, and excess of air pass at once into the lime. chamber. The difficulty in this process is the large volume of diluting nitrogen which accompanies the chlorine, but I believe we shall hear from Mr. Deacon that, notwithstanding this drawback, he has accomplished his end of raking good bleach. ing powder by this process.

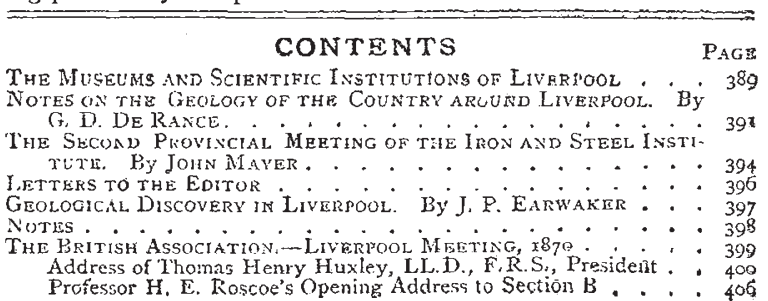

